commercial sample of yeast-nucleic acid cured the disease in 3 out of 14 cases (pigeons), it was not possible to obtain conclusive results with all kinds of simple phosphoruscontaining substances, such as lecithin, glycerophosphates, and phospho-proteins. For these reasons Sshaumann suggests (z. p. p. 347) that phosphorus compounds can only exercise curative effects when acting in conjunction with certain other substances.

With this we conclude the részumé of the more important work on the problem of beri-beri and pass to the consideration of the results of our own experiments.

We have repeated feeding experiments of former workers upon birds (fowls and pigeons) with the various kinds of rice and have confrmed them, and have also confirmed the preventive action of rice bran (polishings). Experiments with an exclusive diet of various pure carbohydrates-starch, inulin, cane sugar, and dextrin - have been carried out, and it was found that such diets induced polyneuritis with the usual symptoms. These results disprove any intoxication hypothesis concerning beri-beri in birds. A daily ration of 0.5 gramme phytin administered to pigeons fed on white irice did ot prevent polyneuritis, and attempts to cure poly. neuritis oy the addition of phytin, edestin, casein, and eggyolk were unswacessfinl. As the latter two substances are relatively rich in organically combined phosphorus the negative results are important. One gramme of dried pressed yeast per day prevented the development of polyneuritis in fowls, and we were also able to confirm the curafive properties of pressed yeast. Yeast-juice obtained by squeezing the ground cells with kieselguhr in a press was found to exert ta curative effect like the original yeast. We have also found that pressed yeast hydrolysed with 20 per oent. sulphurio acid for 2 heurs still retained its ourative properties. As all organic phosphorus compounds are completely hydrolysed ander such conditions, and phosphoric acid has been shown to be without ineluence, it is very improbable that the polyneuritis is the result of a deficiency in phosphorus compownds.

After confirming the results of Fraser and Sianton concerning the beneficial effects of the alcoholic extract of rice polishings, we precipitated a water solution of the extract by means of phospho-tungstic acid, and found that the active substance is precipitated entirely by this reagent and that the filtrate is completely inactive.

The eurative efect of the precipitate decomposed by barpta in the usual way, which is wholly devoid of phosphorus and also free from carbohydrates or protein groups, was tried upon ten pigeons; it was found to be extraordinarily active and cured the birds even when they appeared moribund, striking improvement occurring in from three to ten hours. In several instances birds which were completely paralysed and supposed to be dying in the evening were found next morning with but some trace of lameness.

Polishings appear to contain only a very small amouns of the active substance, and for further progress a very large quantity of polishings must be dealt with.

In conclusion, it appears that the polyneuritis induced in birds by a diet of decorticated and polished rice is not due to the deficien zy of phosphorus compounds, but to the absence of some substance not of protein nature, devoid of phosphorus, soluble in water and acidulated alcohol, dialysable, and presipitated by phospho-tungstic acid, and the precise nature of which is being at present investigated by one of us (C. F.).

We are glad to have this opportunity of expressing our best thanks to Dr. O. J. Martin, $F R$ S., Director of the Lister Institute, for drawing our attention to this subject, and for help and advice in the course of the investigation; and to Dr. Leonard Rraddon of Seremban, Malay States, to whom we are indebted for kindly furnishing an adequate supply of different kinds of rice and rice polishings.

Bibliography,-1. Wemick: Geographisch-Medicinische Studien, Berlin, 1878. 2. Van Leent : Geneeskundig Tijdschrift voor NederlandschIndie, 1880. 3. Takaki. Prevention of Kakke in Japanese Navy, Sei-i-Kwai, 1885, 1886, 1887. 4. Braddon: The Cause and Prevention of Beri-Beri, Tondon, 1907. 5. Eykman: Virchow's Archiv. 143 (1897); Geneeskundig Tijdschrift voor Nederlandseh-Indie, 36 (1838). 6. Griyns: Ibid., 41 1918, B. 733 ; Studies from the Institute for Medical liesearch, Federated Malav States, No. 12, The Etiology of Beri-Beri, 1911. 8. Chamberlain and Vedder: The Philippine Journal of Scrence, June, 1911, vol. vi. 9. Sehaumann: Die itiologie der Beri-Beri unter Beruicksichtigung des Gesamaten Phosphorstofifwechsels, Archiv fir Schiffs- und Tropenhygiene (1910), 14, Beiheft 8. 10. Aron and Hogson: The Philippine Tournal of Science, vol, v., February, 1910.

\section{A NOTE ON THE \\ CARBOLIC ACID COEFFICIENT OF DISINFECTANTS.}

BY F. T. MARCHANT, M.R S I.,

IECTURE ASSISTANT IN THE PUBLIC HFALTH DEPARTMENT OF UNIYERSITY COLLEGE, LONDON.

THE Rideal-Walker method of determining the carbolic acid coefficient of a disinfectant of ten furnishes results which are discrepant-viz., a subculture tube often shows a growth when another tube, containing the same culture exposed to the same dilution of a disinfectant and for a shorter periud of time, fails to do so.

It must be assumed that if the same organism in similar numbers is "present, then concordant results should always be obtained; but owing to the small amount of fluid which the platinum loop employed in the process for inoculation purposes can hold (and it may also be that there is a diminution in the number of living organisms surviving the action of the disinfectant) it is quite possible that occasionally none of these may be picked up with the loop, and therefore no growth can result. To overcome the discrepancy alluded to, amongst other suggestions, THE LANCET Commissioners I advocated the use of a platinum spoon which would hold about three times as much inoculating material as the platinum loop. But, as they pointed out, three or four spoons must be employed; each one being used in turn after being placed on a rack to csol subsequently to sterilisation. This modification has the advantage of employing a larger dose of the organism, but it increases the danger of the diluted disinfectant containing the organism getting contaminated from ontside sources. That this contamination does take place is demonstrated by the fact that organisms other than those experimented with are sometimes found in the subculture tabe.

THE LANCET Commissioners also pointed out that according to their method no disinfectant had a higher carbolic acid coefficient than about 13. The probable explanation of this is, again, the fact that a larger dose of organism is a aded with their spoons than with the platinum loop. Also when working with the separating flask a lower coefficient is obtained than by the Rideal-Walker method as performed in the usual way.

I have recently contrived a small apparatus which works very successfully. By its employment there is no fear of contamination from the air, a large dose of the organism is added, no platinum loops or spoons are required, and the test can on the whole be expeditiously carried out. The apparatus consists of a small glass separating fisk; the part above the stopcock is open to the air, cylindrical in shape, 3 in. long, and nearly 1 in. in diameter; the stem below the stopcock is sarrowed down to a very fine point, so that only a very small drop of fluid can escape. The top is kept plagged with cottonwool (which is only momentarily removed to enable the disinfectant to be added); and on making an experiment the requisite number of these small appliances are sterilised and clamped to a stand. One drop of the typhoid broth is then added, followed by 1 c.c. of the disinfectant solution: and if the worker thinks it necessary he may mix the contents by stirring with a platinum loop. The subculture tubes are inoculated at the proper intervals of time by turning the stopcock, allowing one drop to fall into the tube, and then gently shaking the tube.

When the experiment is finished the whole of the small apparatus may be washed through with a dilute acid, then thoroughly washed in water, the stopcock smeared with glycerine (not vaseline) to make it turn easily, re-plugged, and again sterilised in the hot-air oven, after which they are arranged ready for use.

It may be argued that the addition of as much as one drop of the mixed culture and disinfectant might include an amount of disinfectant which would inhibit growth in the subculture tubes; this, howerer, is not the case when culture tubes are employed containing about 10 c.c. of medium.

1 The Lancet Commission on the Standardisation of Disinfectants. See The LAXCET, Nov. 13th, 20th, and 27th, 1909. 